\title{
Production of geopolymer composites enhanced by nano-kaolin material
}

\author{
Mahmoud M. HASSAAN ${ }^{a}$, Hisham M. KHATER ${ }^{b, *}$, \\ Medhat S. EL-MAHLLAWY ${ }^{b}$, Abdeen M. EL NAGAR ${ }^{b}$ \\ ${ }^{a}$ Al Azhar University, Nasr City, Cairo, Egypt \\ ${ }^{b}$ Housing and Building National Research Centre (HBRC), 87 El-Tahrir St., Dokki, \\ Giza, P.O. Box 1770, Cairo, Egypt
}

Received: February 24, 2015; Revised: May 05, 2015; Accepted: May 11, 2015

(C) The Author(s) 2015. This article is published with open access at Springerlink.com

\begin{abstract}
Nowadays kaolin raw material is usually used to produce nano-kaolin for geopolymer enhancement by using firing method. In the present study, kaolin used was taken from the Naqus Formation (Cambro-Ordovician age), west of Gabal El Gunna, Sinai, Egypt. Nano-kaolin material is an ultrafine material and was prepared from the taken kaolin by the firing process at $800{ }^{\circ} \mathrm{C}$ for $2 \mathrm{~h}$ with a heating rate of $5{ }^{\circ} \mathrm{C} / \mathrm{min}$. Six mixes were prepared and their laboratory specimens were made and cured up to 90 days. Water cooled slag was used as starting material, and sodium hydroxide and sodium silicate were used in the study as activators for the used kaolin. The formed geopolymer mixes with different ratios $(1 \%, 1.5 \%, 3 \%, 5 \%$, and $7 \%)$ of nano-kaolin as a partial replacement for the raw kaolin were investigated. Gelenium Ace super plasticizer was added in the ratio of $4 \%$ from the dry weight to ensure good dispersing of the used nano clay. Results showed that increasing the percentage of nano-kaolin up to 3\% results in an enhancement in the mechanical properties as compared with the control mix up to 90 days of curing, while higher ratios are not preferable where they lead to agglomeration of the added nano materials and matrix dilution.
\end{abstract}

Keywords: geopolymer; nano-kaolin; sodium silicate; slag

\section{Introduction}

Geopolymers are inorganic polymeric materials, first developed by Joseph Davidovits in the 1970s. Geopolymerization involves a chemical reaction between alumino-silicate oxides and alkali metal silicate solutions under highly alkaline conditions, yielding amorphous to semi-crystalline threedimensional polymeric structures, which consist of $\mathrm{Si}-\mathrm{O}-\mathrm{Al}$ bonds [1] and give a fresh insight into this

\footnotetext{
* Corresponding author.

E-mail: hkhater4@yahoo.com
}

class of inorganic polymers.

Geopolymerization is being considered for replacing traditional structural materials and offers a possible solution to the immobilization of toxic and radioactive wastes as well as the treatment of industrial wastes to produce value added construction materials. Therefore, there is an increasing need for multiple source materials to be jointly geopolymerised to maximally exploit the respective properties of the individual sources regarding compressive strength, stability, and durability [2].

Geopolymers can be thought as a new generation binder that can be substituted for the calcium silicate hydrate which is an essential component of Portland 
cement, where they have a lower impact on global warming than ordinary Portland cement (OPC), but on the other side, they have a higher environmental impact regarding other impact categories [3].

As one ton of OPC manufactured, nearly one ton of $\mathrm{CO}_{2}$ is produced depending on the production process adopted [4]. Cement plants are reported to emit up to 1.5 billion tons of $\mathrm{CO}_{2}$ into the atmosphere annually $[5,6]$. Hence, environmental preservation has become a driving force behind the search for new sustainable and environmentally friendly composites to replace conventional concrete produced from the OPC.

It has been established that the main product of slag hydration is essentially the same as the principal product formed when PC hydrates [7,8], i.e., calcium silicate hydrate $(\mathrm{CSH})$. The main factors known to influence the hydraulic activity of slag cement include chemical composition, glass content, fineness, activator content, curing temperature, and water to cementitious material ratio [9]. Ground granulated blast furnace slag (GGBFS) has been used for decades as partial replacement material in concrete and has well established standards describing their use [10-13].

During the period of the second half of the previous century, the terms "nano science" and "nanotechnology" were not yet familiarly used as today; however, they were really practicized and successfully applied to the progress in the field of material science and technology. Concrete performance is strongly dependent on nano-sized dimensions of solid materials such as CSH particles, or voids such as the gel porosity in the cement matrix and the transition zone at the interface of cement paste with aggregate or steel reinforcement; typical properties affected by nano-sized particles are strength, durability, shrinkage, and steel-bond. The word "nano" means anything of size $10^{-9} \mathrm{~m}$; nanoparticles are solid particles of sizes in the range of $1-100 \mathrm{~nm}$.

Kuo et al. [14] studied the compressive and flexural strengths of cement mortars enhanced with $\mathrm{SiO}_{2}$ and $\mathrm{Fe}_{2} \mathrm{O}_{3}$ nanoparticles. It was found that the nanoparticles dispersed uniformly in a cement paste will accelerate cement hydration due to their high activity [15]. The nanoparticles will fill pores, leading to the increased strength and improving the microstructure of cement and the interface between the cement paste and aggregates in concrete. It was also found that nano $\mathrm{Fe}_{2} \mathrm{O}_{3}$ exhibits a self-sensing of strain capability which can be useful for structural health monitoring [15].

Khater et al. [16] studied alkaline activation of latent hydraulic water cooled slag (WCS) by $6 \%$ sodium hydroxide. They added nano clay produced from firing the kaolin material at $800{ }^{\circ} \mathrm{C}$ for $2 \mathrm{~h}$ with a heating rate of $5{ }^{\circ} \mathrm{C} / \mathrm{min}$ to the geopolymer mix in the ratio of 0 up to $7 \%$ of the dry weight. The results showed that increasing the percentage of nano clay up to $1 \%$ leads to an enhancement in the mechanical properties as compared with the control mix up to 90 days, while higher ratios lead to matrix dilution.

El-Sayed et al. [17] studied the durability of the water cooled slag in $5 \% \mathrm{MgSO}_{4}$, where the better microstructure and high resistivity clarify that the activation by $3: 3$ sodium hydroxide and sodium silicate is better than using $2 \%$ and $6 \%$ of sodium hydroxide. Khater [18] studied the effect of cement kiln dust on alkali activated slag and its resistivity against sulfate attack, indicating that the use of $25 \%$ cement kiln dust to slag material leads to good enhancement in geopolymer structure. It was also studied by Khater and Zedane [19] that the effect of cement kiln dust on activation of geopolymer composites containing phosphogypsum and fly ash results in very good enhancement in thermal stability up to $1200{ }^{\circ} \mathrm{C}$ by using $10 \%$ and $20 \%$ phosphogypsum.

Khater [20] also studied thermal and acid resistance of alkali activated slag geopolymer, and the results illustrated that geopolymer material prepared using alkali activated slag exhibits large change in compressive strength with increasing firing temperature from 300 to $1000{ }^{\circ} \mathrm{C}$ and possesses an enhancement in thermal stability as compared to concrete specimens. Replacement of GGBFS by $15 \%$ air cooled slag resists thermal deterioration up to $1000{ }^{\circ} \mathrm{C}$. It was suggested to be suitably applied in the refractory insulation applications as well as for production of nuclear concrete reactors. On the other hand, geopolymer mixes exhibit low stability subjected to different concentrations from the mix of nitric and hydrochloric acid in equal ratio (1:1). Khater et al. [21] also studied the alkaline activation of latent hydraulic WCS by using $6 \%$ sodium hydroxide with nano silica. It was concluded that increasing the percentage of nano silica results in an enhancement in the mechanical properties as compared with the control mix up to 90 days of curing.

The main purpose of this work is to study the preparation of geopolymer material by alkaline activation of kaolinite and amorphous water cooled slag material. The effect of addition of different ratios of 
nano clay on alkali activated kaolinite and water cooled slag has be investigated as well as the impacts on mechanical and microstructural characteristics. X-ray florescence, X-ray diffraction (XRD), Fourier transform infrared spectroscopy (FTIR), and scanning electron microscopy (SEM) were used to identify the chemical, mineralogical, and microstructural properties of geopolymer composites. The compressive strength measurement was executed to evaluate the mechanical performance of the geopolymer specimens.

\section{Experimental procedures}

\section{1 Materials}

Material used in this investigation was kaolin, which was collected from Sinai, west of Gabal El Gunna, Egypt. Ground granulate blast furnace slag (GGBFS) was supplied by the Iron and Steel Factory-Helwan, Egypt. Sodium hydroxide $(\mathrm{NaOH})$ with purity of $99 \%$ in the form of pellets and sodium silica $\left(\mathrm{Na}_{2} \mathrm{SiO}_{3}\right)$ were used as alkali activators, obtained from Piochem Co., Egypt. Nano-scale kaolin particles were prepared in the HBRC lab from the kaolin raw material, as will be mentioned later. The chemical compositions of the starting raw materials are given in Table 1. Mineralogical characterization of the raw materials was done using XRD analysis in powder form as represented in Fig. 1. The pattern shows that water cooled slag is composed mainly of amorphous materials and akermanite phase $\left(\mathrm{Ca}_{2} \mathrm{MgSi}_{2} \mathrm{O}_{7}\right)$, while kaolin raw material is composed of kaolinite mineral with minor amount of quartz and anatase minerals.

\section{2 Synthesis of nano-clay}

Nano-kaolin particles were synthesized by firing the high-purity kaolin material at $800{ }^{\circ} \mathrm{C}$ for $2 \mathrm{~h}$ with a heating rate of $5{ }^{\circ} \mathrm{C} / \mathrm{min}$ to form an amorphous nano precursor. Firing of the raw kaolin provided the formation of nano clay particles with the average particle size of $50-100 \mathrm{~nm}$. The kaolin raw material before firing has a grain size less than $10 \mu \mathrm{m}$ as indicated from the transmission electron microscopy (TEM) (Fig. 2). Figure 3 compares the XRD patterns of kaolin and nano-kaolin materials and confirms the distorted and dehydrated type of the formed amorphous nano-kaolin material.

\section{3 Geopolymerization and curing}

Geopolymer was made by hand-mixing the raw sieved materials with each mixture passing sieve of diameter $90 \mu \mathrm{m}$ with the alkaline solution for $10 \mathrm{~min}$ and a further $5 \mathrm{~min}$ in a mixer. The mixing process was carried out using $3 \% \mathrm{NaOH}$ and $3 \% \mathrm{Na}_{2} \mathrm{SiO}_{3}$ of dry mixes based on previous investigation [22]. The water to binder material ratio was about 0.32 by mass. Six mixes were prepared for the investigation. Nano-kaolin

Table 1 Chemical composition of the starting raw materials

\begin{tabular}{cccccccccccccccc}
\hline Material (\%) & $\mathrm{SiO}_{2}$ & $\mathrm{Al}_{2} \mathrm{O}_{3}$ & $\mathrm{Fe}_{2} \mathrm{O}_{3}$ & $\mathrm{CaO}$ & $\mathrm{MgO}$ & $\mathrm{SO}_{3}$ & $\mathrm{~K}_{2} \mathrm{O}$ & $\mathrm{Na}_{2} \mathrm{O}$ & $\mathrm{TiO}_{2}$ & $\mathrm{MnO}$ & $\mathrm{P}_{2} \mathrm{O}_{5}$ & $\mathrm{Cl}^{-}$ & L.O.I. & Total & $\mathrm{Note}$ \\
\hline Water cooled slag (GGBF) & 35.36 & 12.69 & 0.48 & 31.72 & 5.08 & 2.35 & 1.52 & 1.23 & 0.55 & 4.72 & 0.031 & 0.24 & 0.03 & 99.89 & $\mathrm{BaO}=3.63$ \\
Kaolin raw & 49.24 & 33.41 & 0.33 & 2.68 & 0.00 & 0.54 & 0.12 & 0.08 & 1.45 & 0.33 & 0.21 & 0.16 & 11.35 & 99.86 & - \\
Nano-kaolin & 56.14 & 38.21 & 0.38 & 0.07 & 0.37 & 0.18 & 0.00 & 0.02 & 1.14 & 0.26 & 0.00 & 0.00 & 3.13 & 99.89 & - \\
\hline
\end{tabular}

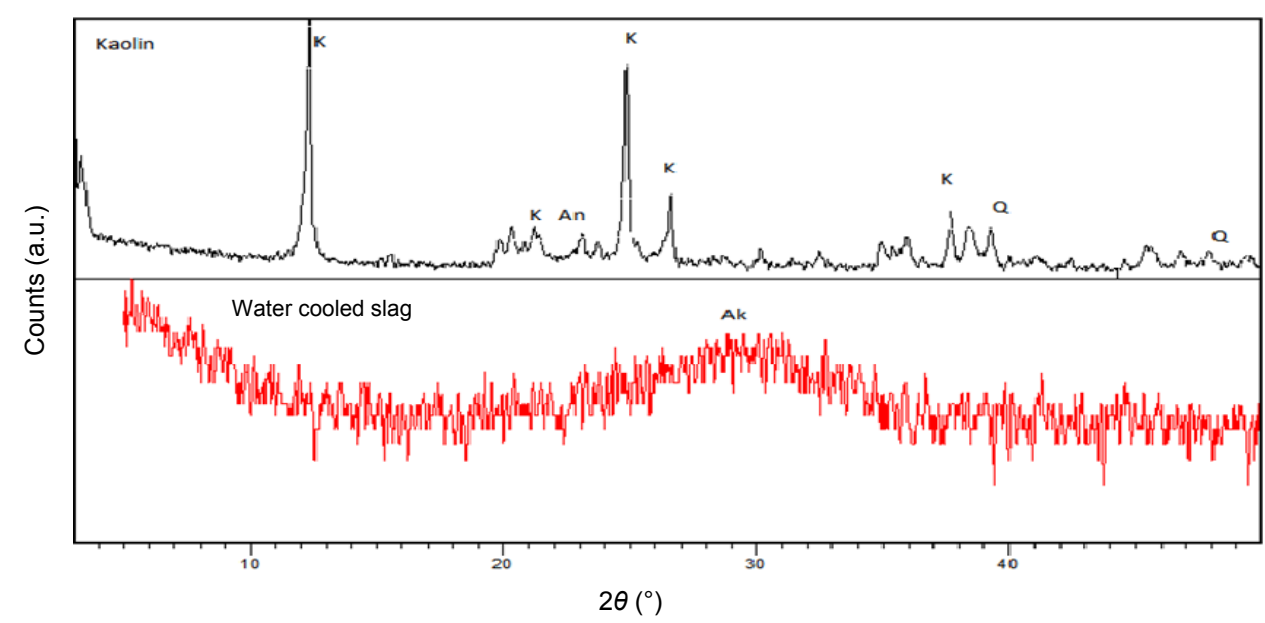

Fig. 1 XRD patterns for the starting raw materials $(\mathrm{K}=$ kaolin, $\mathrm{Q}=$ quartz, $\mathrm{An}=$ anatase, $\mathrm{Ak}=$ akermanite $)$. 


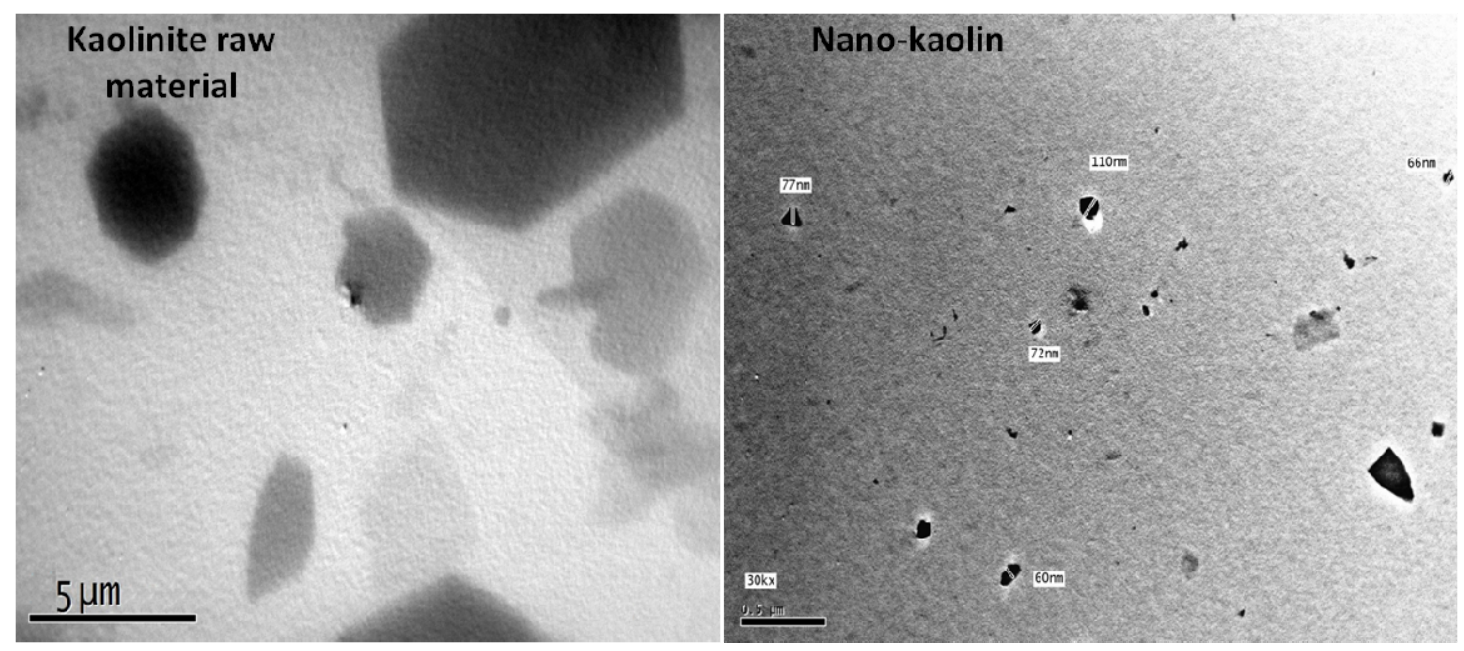

Fig. 2 TEM micrographs of the kaolin (left) and nano-kaolin (right) materials.

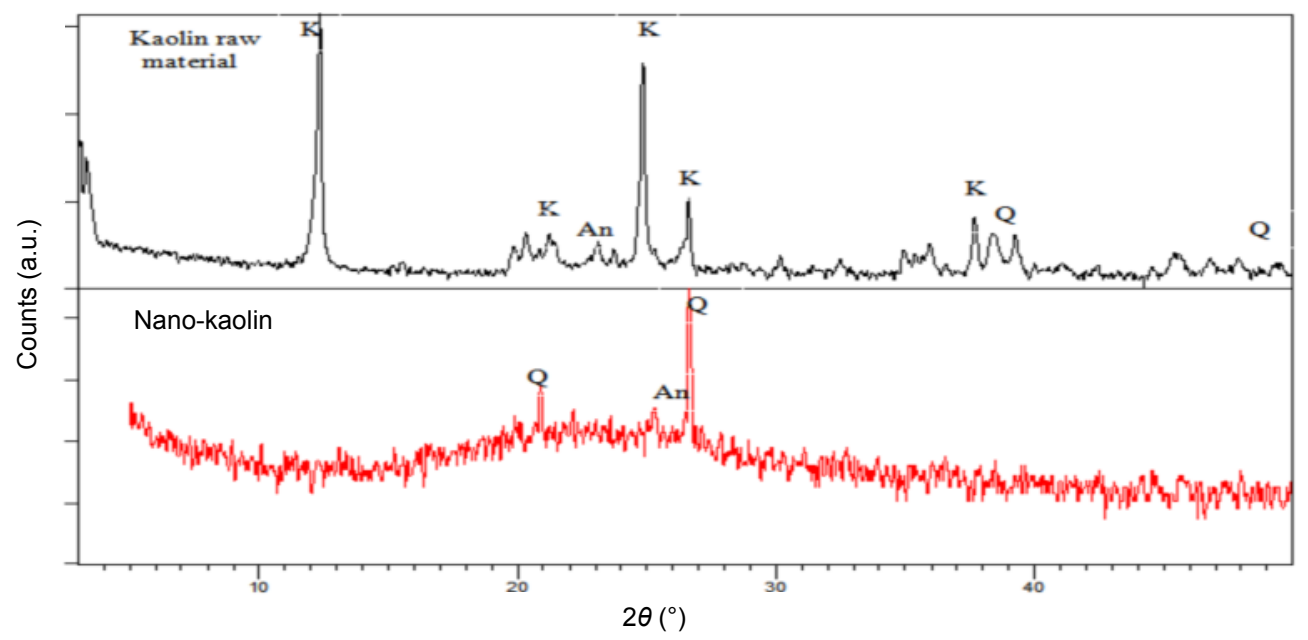

Fig. 3 XRD patterns of the kaolin raw material before (upper) and after (lower) firing at $800{ }^{\circ} \mathrm{C}(\mathrm{K}=\mathrm{kaolin}, \mathrm{Q}=\mathrm{quartz}$, $\mathrm{An}=$ anatase).

was added to the mixes in ratios of $0,1 \%, 1.5 \%, 3 \%, 5 \%$, and $7 \%$ as illustrated in Table 2, and mixed well with part of the used water using a magnetic stirrer; the rest of water was mixed with $3 \% \mathrm{NaOH}+3 \% \mathrm{Na}_{2} \mathrm{SiO}_{3}$ as alkali activators, and then added to the mixes followed by the nano-kaolin (NK) and finally 4\% super plasticizer-Gelenium Ace (SP). Paste mixtures were casted into $25 \mathrm{~mm} \times 25 \mathrm{~mm} \times 25 \mathrm{~mm}$ cubic shaped moulds, vibrated, compacted, and then sealed with a lid to minimize any loss of evaporable water.

All mixes were left to be cured undisturbed at ambient temperature for $24 \mathrm{~h}$, and then cured at a temperature of $38{ }^{\circ} \mathrm{C}$ and $100 \%$ relative humidity. At the end of the curing process, the specimens were subjected to the compressive strength measurements and then the resulted specimens were subjected for stopping of the hydration process by drying the crushed specimens for $24 \mathrm{~h}$ at $105{ }^{\circ} \mathrm{C}$ [18], and then preserved in

Table 2 Composition and proportion of the studied mixes

\begin{tabular}{|c|c|c|c|c|c|c|c|c|c|}
\hline Mix & Kaolin (\%) & Slag (\%) & NK (\%) & $\mathrm{NaOH}(\%)$ & $\mathrm{Na}_{2} \mathrm{SiO}_{3}(\%)$ & SP (\%) & Total $\mathrm{M}_{2} \mathrm{O} / \mathrm{Al}_{2} \mathrm{O}_{3}$ & $\mathrm{SiO}_{2} / \mathrm{Al}_{2} \mathrm{O}_{3}$ & Total $\mathrm{MO}_{2} / \mathrm{SiO}_{3}$ \\
\hline M0 & 50.0 & 50 & 0 & 3 & 3 & 4 & 0.31 & 3.39 & 0.07 \\
\hline M1 & 49.0 & 50 & 1.0 & 3 & 3 & 4 & 0.30 & 3.38 & 0.07 \\
\hline M2 & 48.5 & 50 & 1.5 & 3 & 3 & 4 & 0.30 & 3.38 & 0.07 \\
\hline M3 & 47.0 & 50 & 3.0 & 3 & 3 & 4 & 0.30 & 3.38 & 0.07 \\
\hline M4 & 45.0 & 50 & 5.0 & 3 & 3 & 4 & 0.30 & 3.38 & 0.07 \\
\hline M5 & 43.0 & 50 & 7.0 & 3 & 3 & 4 & 0.30 & 3.38 & 0.07 \\
\hline
\end{tabular}


a well tight container until the time of testing.

\section{4 Methods of investigation}

Chemical analysis was carried out using Axios wave length dispersion X-ray fluorescence (WD-XRF) sequential spectrometer (Panalytical, the Netherlands, 2009). The XRD analysis was carried out using a Philips PW3050/60 diffractometer. The data was identified according to the XRD software. Perkin Elmer FTIR Spectrum RX1 spectrometer was used to evaluate the functional groups in the samples. Small amounts of potassium bromide $(\mathrm{KBr})$ and geopolymer powder were mixed and placed in the sample holder, and then the mixes were pressed at $295 \mathrm{MPa}$ for $2 \mathrm{~min}$ to produce specimens for examination. The wave number was ranging from 400 to $4000 \mathrm{~cm}^{-1}$ [23,24].

Compressive strength tests were carried out using five-ton German Brüf pressing machine with a loading rate of $100 \mathrm{MPa} / \mathrm{s}$ determined according to ASTMC109 [22]. The microstructure of the hardened specimens was studied using SEM Inspect S (FEI Company, the Netherlands) equipped with an energy dispersive X-ray analyzer (EDX). The morphology and microstructure of the prepared nanomaterials were characterized by TEM (Model JEM-2100, JEOL, Japan). The samples were prepared by sonication for $3 \mathrm{~min}$ as synthesizing carbon nanotubes in $5 \mathrm{~mL}$ ethanol and dropping the suspension onto a $\mathrm{Cu}$ TEM grid with a carbon film. Removing the free water was accomplished by drying the crushed specimens for $24 \mathrm{~h}$ at $105{ }^{\circ} \mathrm{C}[18]$.

\section{Results and discussion}

\section{1 Compressive strength}

Results of compressive strength of the hardened geopolymer as a function of various nano-kaolin content cured up to 90 days are shown in Fig. 4. Results show the increase of strength in all mixes as the hydration age progressed. This is attributed to the continuous pozzolanic reaction of slag and kaolin pastes. Activation of alumino-silicate components using $3 \% \mathrm{NaOH}+3 \% \mathrm{Na}_{2} \mathrm{SiO}_{3}$ achieves better compressive strength where it provides a high $\mathrm{pH}$ (more than 12) as mentioned before [14], suitable for kaolin and GGBFS activation and enhancing better geopolymeric structure. It can be noticed that the compressive strength values are slightly low as half of the reactant is kaolinite

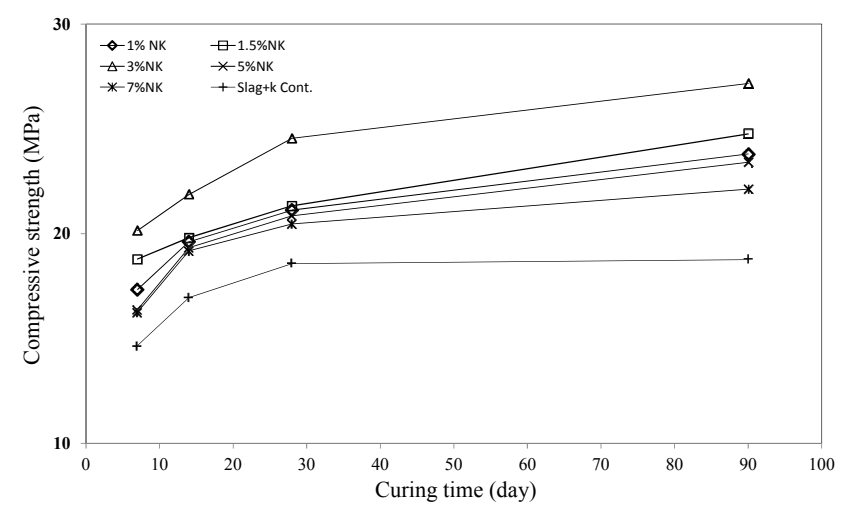

Fig. 4 Compressive strength of alkali activated geopolymer specimens as a function of various dosages of nano-kaolin (NK) cured up to 90 days.

material in the crystalline low reactive state, while thermal treatment leads to transformation of the crystalline into amorphous reactive one, so most of the gained strength arises from the granulated slag constituents in addition to the enhancement effect of the added nanomaterials.

Using super plasticizer for giving a good workability of the geopolymer mixes positively affects the compressive strength value of the specimen. It is also noticed an increase in strength with nano-kaolin addition up to $3 \%$, while it decreases by the addition of $5 \%$ nano-kaolin. All the mixes with nano-kaolin addition are better than the control mix (M0). The good results may be due to the fact that highly reactive nano-kaolin consumes the liberated hydrated lime from hydration reaction and results in the formation of $\mathrm{CSH}$ that acts as nucleating sites for geopolymer formation and accumulation [25]. Also, the added nano-kaolin positively affects the reaction by contributing its alumina and silicon oxides into geopolymer formation. However, the ultrafine composition hinders the progress of the reaction if added in high dose. But using 3\% of nano-kaolin additive achieves the best compressive strength after 90 days of curing compared to other mixes. This is due to the good dispersion of the added nanomaterial forming nucleation sites for geopolymer formation and accumulation and so resulting in formation of compact microstructure, where the dissolved $\mathrm{Ca}$ species react with the amorphous nanomaterials forming CSH that acts as nucleating sites for formation and accumulation of dissolved species leading to a rapid hardening. However the increased dose of the nanomaterials leads to the formation of agglomerate which hinders the intact between the reacting materials, the increased porosity in the 
medium, and the increased carbonation depth, weakening the resulted structure $[25,26]$.

\section{2 Scanning electron microscopy}

The microstructure of the fired raw kaolin reveals the plate-like sheets dispersed all over the matrix (Fig. 5). On the other hand, alkaline activation of kaolin and slag mix leads to the dissolution of the alumino-silicate materials forming tetrahedral polymer that links together forming chains spread over the surface (Fig. $6(\mathrm{a})$ ). Partial substitution of kaolin by $1 \%$ nano-kaolin leads to the enhancement in the morphological structure of the resulting geopolymer chains, where the nanomaterial acts as nucleation material for geopolymerization reaction and so facilitates the agglomeration of the reaction products as revealed in Fig. 6(b) where coherent geopolymer plates are formed.

Further increase in the nano-kaolin addition (3\%) (Fig. 6(c)) results in an enhancement in the morphological structure of the resulting geopolymer, illustrated from the massive geopolymer plats that fill most of the matrix. The added nanomaterial acts as a seeding side for geopolymer in addition to the added


Fig. 6 SEM micrographs of geopolymer mixes of (a) M0, (b) M1, (c) M3, and (d) M5 cured for 90 days.

amorphous alumino-silicate source from the nano-kaolin that enriches the morphological shape and leads to the enhancement in mechanical properties as revealed previously in the compressive strength results. The increase in the percentage of nano-kaolin up to $3 \%$ results in the strength increase as compared to the control mix (M0) that has no nano-kaolin, while further increase in the nanomaterial more than 5\% (Fig. 6(d)) leads to the agglomeration of nanomaterial and so acts

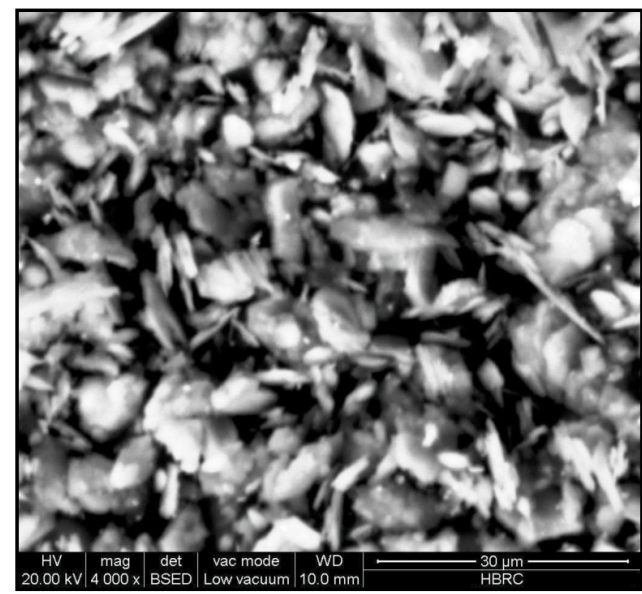

Fig. 5 SEM micrograph of the raw kaolin.

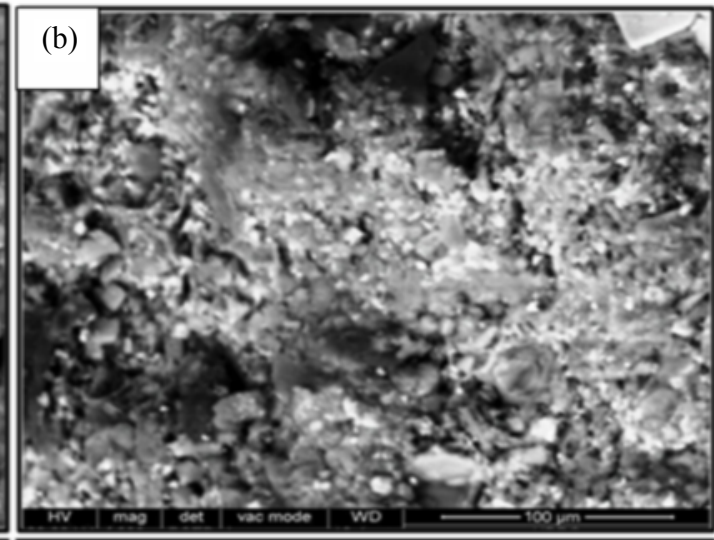


as a barrier against the formation of the three-dimensional network of the geopolymer chains which in turn reflects negatively on the mechanical characteristics of the resulting products. This is confirmed from the lower compressive strength values of mixes containing $5 \%$ and $7 \%$ nano-kaolin as compared with that contains 3\% nano-kaolin. In spite of that, the strength of the $7 \%$ nano-kaolin enhanced geopolymer exceeds that of the control mix. This means that the nanomaterial plays a reinforcement role as revealed from the amorphous structure of its constituents giving a dense structure.

\section{3 Fourier transform infrared spectroscopy}

Figure 7 shows the FTIR spectra of raw kaolin and geopolymer products cured for 90 days synthesized using $\mathrm{NaOH}$ and sodium silicate solution and with addition of $1 \%, 3 \%$, and $7 \%$ nano-kaolin.

The FTIR bands are as follows: stretching vibrations of $\mathrm{O}-\mathrm{H}$ band of kaolinite hydroxyl at 3695 and $3619 \mathrm{~cm}^{-1}$, stretching vibrations of $\mathrm{CO}_{2}$ located at about 1437 and $876 \mathrm{~cm}^{-1}$, asymmetric stretching vibration (T-O-Si) at $1027-1032 \mathrm{~cm}^{-1}$ where $\mathrm{T}=\mathrm{Si}$ or $\mathrm{Al}$, stretching vibration of $\mathrm{Si}-\mathrm{O}-\mathrm{Si}$ at $912 \mathrm{~cm}^{-1}$, symmetric stretching vibration $(\mathrm{Si}-\mathrm{O}-\mathrm{Si}$ and $\mathrm{Al}-\mathrm{O}-\mathrm{Si})$ in the region $698-700 \mathrm{~cm}^{-1}$, and bending vibration $(\mathrm{Si}-\mathrm{O}-\mathrm{Si}$ and $\mathrm{O}-\mathrm{Si}-\mathrm{O})$ in the region $460-475 \mathrm{~cm}^{-1}$. It can be observed that the addition of nano-kaolin provides the distortion of the intercalation of kaolinite chains and consequently increases its reactivity.

Also the main asymmetric band at $1027-1032 \mathrm{~cm}^{-1}$ turns to be wider with the increase of the added nanomaterials up to $3 \%$, reflecting the increase of the geopolymerization. The bending and symmetric bands which are intense in kaolinite pattern turned to be diminished as most of $\mathrm{Al}$ and $\mathrm{Si}$ incorporate in the geopolymerization reaction. Further increase in the nanomaterial $(7 \%)$ leads to decrease in the symmetrical band of T-O-Si, which may be due to the dilution effect by added nanomaterial as well as the insufficient wetting by the effect of the added nanomaterial resulting in agglomeration as elucidated clearly from the SEM (Fig. 6).

\section{Conclusions}

The main conclusions derived from this work can be summarized as follows:

(1) Enhancement of mechanical and microstructural properties with nano-kaolin addition up 3\% is realized, while further increase results in lowering in the characteristics of the reaction product.

(2) Mechanical and microstructural properties are positively affected with the super plasticizer addition, as

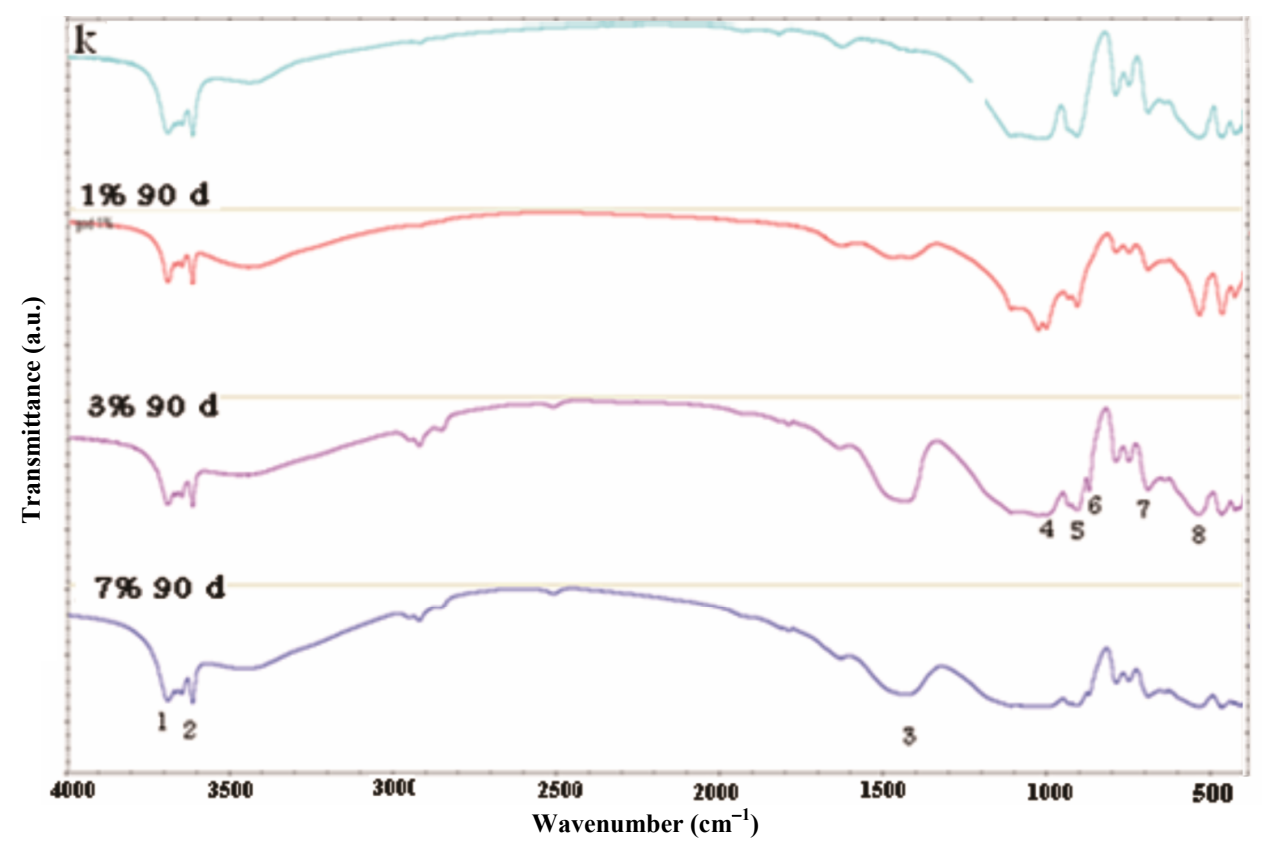

Fig. 7 FTIR spectra of cured geopolymer samples incorporating nano-kaolin material in the ratios of $1 \%, 3 \%$, and $7 \%$ as compared with the raw kaolin material. 1, 2: stretching vibrations of $\mathrm{O}-\mathrm{H}$ band; 3 : stretching vibration of $\mathrm{CO}_{2} ; 4$ : asymmetric stretching vibration (T-O-Si); 5 : stretchly vibration $(\mathrm{Si}-\mathrm{O}-\mathrm{Si}) ; 6$ : symmetric stretching vibration of $\mathrm{CO}_{2} ; 7$ : symmetric stretching vibration ( $\mathrm{Si}-\mathrm{O}-\mathrm{Si}$ and $\mathrm{Al}-\mathrm{O}-\mathrm{Si})$; 8: bending vibration $(\mathrm{Si}-\mathrm{O}-\mathrm{Si}$ and $\mathrm{O}-\mathrm{Si}-\mathrm{O})$. 
the nanomaterial is effectively dispersed in the matrix leading to the formation of more nucleation sites for geopolymer formation and accumulation.

(3) Addition of nano-kaolin provides an enhancement in geopolymer microstructure, leading to the formation of homogeneous matrix with little points of defects forming compact structure and therefore an increase in the compressive strength value as compared with the specimen without nano-kaolin.

\section{Acknowledgements}

The authors would like to thank the geologist Yousry Abu Qamar who works in the Middle East Mining Investment Co. (Egypt) for the facilities he offered in the field work.

Open Access: This article is distributed under the terms of the Creative Commons Attribution License which permits any use, distribution, and reproduction in any medium, provided the original author(s) and the source are credited.

\section{References}

[1] Davidovits J. Chemistry of geopolymeric systems, terminology. In Proceedings of the 2nd International Conference on Geopolymer, Saint-Quentin, France, 1999: 9-39.

[2] Krivenko PV. Peculiarity of formation of the contact zone (slag alkaline cement mineral wool). In Second International Symposium on Cement and Concrete Technology, Istanbul, Turkey, 2000: 553-561.

[3] Habert G, de Lacaillerie JB, Roussel N. An environmental evaluation of geopolymer based concrete production: Reviewing current research trends. J Clean Prod 2011, 19: 1229-1238.

[4] McLellan BC, Williams RP, Lay J, et al. Costs and carbon emissions for geopolymer pastes in comparison to ordinary Portland cement. J Clean Prod 2011, 19: 1080-1090.

[5] Hasanbeigi A, Price L, Lin E. Emerging energy-efficiency and $\mathrm{CO}_{2}$ emission-reduction technologies for cement and concrete production: A technical review. Renew Sust Energ Rev 2012, 16: 6220-6238.

[6] Ali MB, Saidur R, Hossain MS. A review on emission analysis in cement industries. Renew Sust Energ Rev 2011, 15: 2252-2261.

[7] Muntasser TZ. Properties and durability of slag based cement in the Mediterranean environment. Ph.D. Thesis. University of Surrey, 2002.

[8] Neville AM. Properties of Concrete, 4th edn. Longman Scientific \& Technical Ltd., 1995.

[9] ACI Committee 266 1R-87. Ground granulated blast-furnace slag as a cementitious constituent in concrete. 1987.

[10] Concrete Society. The use of GGBS and PFA in concrete. Techn Rep 1991, 40: 142.

[11] Sersale R, Amicarelli V, Frigione G, et al. A study on the utilization of an Italian steel slag. In Proceedings of the 8th International Congress on the Chemistry of Cement, Rio de Janeiro, Brazil, 1986: 194-198.

[12] Shi C. Steel slag-Its production, processing, characteristics, and cementitious properties. J Mater Civil Eng 2004, 16: 230-236.

[13] Ye N, Yang J, Ke X, et al. Synthesis and characterization of geopolymer from Bayer red mud with thermal pretreatment. $J$ Am Ceram Soc 2014, 97: 1652-1660.

[14] Kuo W-Y, Huang J-S, Lin C-H. Effects of organo-modified montmorillonite on strengths and permeability of cement mortars. Cement Concrete Res 2006, 36: 886-895.

[15] Li H, Xiao H, Ou J. A study on the mechanical and pressure sensitive properties of cement mortar with nanophase materials. Cement Concrete Res 2004, 34: 435-438.

[16] Khater HM, El-Sabbagh BA, Fanny M, et al. Effect of nano-silica on alkali activated water-cooled slag geopolymer. In Proceedings of the Second International Conference on Microstructural-related Durability of Cementitious Composites, Amsterdam, the Netherlands, 2012: 11-13.

[17] El-Sayed HA, Abo El-Enein SA, Khater HM, et al. Resistance of alkali activated water-cooled slag geopolymer to sulfate attack. Ceram-Silikaty 2011, 55: 153-160.

[18] Khater HM. Effect of cement kiln dust on geopolymer composition and its resistance to sulphate attack. Green Materials 2013, 1: 36-46.

[19] Khater HM, Zedane SR. Geopolymerization of industrial by-products and study of their stability upon firing treatment. International Journal of Engineering and Technology 2012, 2: 308-316.

[20] Khater HM. Studying the effect of thermal and acid exposure on alkali-activated slag geopolymer. $\mathrm{Adv} \mathrm{Cem}$ Res 2014, 26: 1-9.

[21] Khater HM, El-Sabbagh BA, Fanny M, et al. Effect of nano-clay on alkali activated water-cooled slag geopolymer. British Journal of Applied Science \& Technology 2013, 3: 764-776.

[22] ASTM International. ASTM C109M-12, Standard test method for compressive strength of hydraulic cement mortars. ASTM International, West Conshohocken, PA, USA, 2012.

[23] Panias D, Giannopolou IP, Perraki T. Effect of synthesis parameters on the mechanical properties of fly ash-based geopolymers. Colloid Surface A 2007, 301: 246-254.

[24] Bakharev T. Thermal behaviour of geopolymer prepared using class $\mathrm{F}$ fly ash and elected temperature curing. Cement Concrete Res 2006, 36: 1134-1147.

[25] Khater HM. Effect of calcium on geopolymerization of aluminosilicate wastes. J Mater Civ Eng 2012, 24: 92-101.

[26] Khater HM. Effect of silica fume on the characterization of the geopolymer materials. International Journal of Advanced Structural Engineering 2013, 5: 12. 